\title{
Study of Water Vapor Variations Associated with Meso- $\gamma$ Scale Convection: Comparison between GNSS and Non-Hydrostatic Model Data
}

\author{
Masanori Oigawa $^{1}$, Eugenio Realini ${ }^{1,2}$, and Toshitaka Tsuda ${ }^{1}$ \\ ${ }^{1}$ Research Institute for Sustainable Humanosphere (RISH), Kyoto University, Gokasho, Uji, Kyoto, Japan \\ ${ }^{2}$ Geomatics Research \& Development (GReD) srl, Via Cavour 2, Lomazzo, Como, Italy
}

\begin{abstract}
Water vapor variations associated with a meso- $\gamma$ scale convection were investigated using GNSS (Global Navigation Satellite System) derived PWV (precipitable water vapor) and high resolution numerical model data with a $250 \mathrm{~m}$ horizontal grid interval. A rapid increase of GNSS-derived PWV that occurred prior to the initiation of surface rainfall was well simulated by the numerical model.

In the model, PWV values began to increase 16 min before the rainfall occurred at the surface. A local maximum of PWV was formed because of the generation of shallow free convection and surface water vapor flux convergence due to a lifting of an air parcel at approximately $1 \mathrm{~km}$ elevation by a preceding surface wind convergence. Due to the existence of a stable inversion layer between 2.2 and $3.5 \mathrm{~km}$ elevation, the shallow free convection took $11 \mathrm{~min}$ to rise above the inversion layer to form a deep convection. These results suggest that observation of local distributions of GNSS-derived PWV is useful for monitoring the generation of deep moist convection.

(Citation: Oigawa, M., E. Realini, and T. Tsuda, 2015: Study of water vapor variations associated with meso- $\gamma$ scale convection: Comparison between GNSS and non-hydrostatic model data. SOLA, 11, 27-30, doi:10.2151/sola.2015-007.)
\end{abstract}

\section{Introduction}

Water vapor is a source of energy for moist convection and has an influence on its developments. Therefore, understanding relationships between variations of water vapor and moist convective activities is important for the prediction of heavy rainfall. For example, it is reported that initiations of localized heavy rainfall are affected by inhomogeneous distributions of surface water vapor in the meso- $\gamma$ scale by reducing CIN (convective inhibition) (Bodine et al. 2010).

In Japan, studies of moisture variations associated with moist convection have been conducted by analyzing PWV (precipitable water vapor) derived from a nationwide GNSS (Global Navigation Satellite System) observation network known as GEONET (GNSS Earth Observation Network System), with mean inter-station distances of approximately $20 \mathrm{~km}$. GEONET studies have reported that water vapor variations precede initiations of moist convections (Seko et al. 2007; Inoue and Inoue 2007). However, the horizontal resolution of GEONET is not high enough to capture the fine structure of a water vapor field associated with a convection cell since the horizontal scale of isolated convection is on the order of a couple of $\mathrm{km}$.

A few observational studies have been conducted to investigate relationships between water vapor variations and meso- $\gamma$ scale convections by using regional GNSS networks with resolutions lower than $10 \mathrm{~km}$. Seko et al. (2004) employed 75 GPS receivers within an area of $20 \times 20 \mathrm{~km}^{2}$ around Tsukuba, Japan and analyzed the thickening of the humid boundary layer before

Corresponding author: Masanori Oigawa, Research Institute for Sustainable Humanosphere (RISH), Kyoto University, Gokasho, Uji, Kyoto 6110011, Japan. E-mail: masanori_ohigawa@rish.kyoto-u.ac.jp. (C)2015, the Meteorological Society of Japan. the generation of a thunderstorm by using a tomography method and GNSS derived slant path delay (SPD) data (Shoji et al. 2004). Realini et al. (2012) and Sato et al. (2013) installed 17 GNSS stations with a horizontal spacing of 1-2 km near Uji campus of Kyoto University, which is located south of Kyoto prefecture, Japan. They succeeded to improve the horizontal resolution of the retrieved PWV maps by analyzing PWV from high elevation SPDs. However, it is difficult to understand physical relationships between water vapor variations and the occurrence of meso- $\gamma$ scale convections only from the information of observed PWV and surface rainfall. Therefore, the objective of this study is to clarify the cause for meso- $\gamma$ scale water vapor fluctuations prior to moist convections by conducting a numerical downscaling experiment of a mesoscale non-hydrostatic model and comparing observed PWV data with output model data.

This manuscript is organized as follows: Section 2 describes analytical results based on observational data, such as weather radar, GNSS-derived PWV, and rain-gauge. Section 3 describes the explanation about the analyzed model and its analysis result. Relationships between simulated surface rainfall and simulated PWV and the associated three-dimensional movement of water vapor were the focus of this analysis. Discussion and summary are presented in Section 4.

\section{Observational results}

\subsection{Synoptic conditions and the rainfall system}

This study focuses on a heavy rainfall event on August 13-14, 2012, around Uji, Kyoto. Ishihara et al. (2013) reported that MCSs (meso-scale convective systems) produced $400 \mathrm{~mm}$ of accumulated rainfall in $13 \mathrm{~h}$ due to unstable atmospheric conditions, i.e. the CAPE (convective available potential energy) was $2340 \mathrm{~J} \mathrm{~kg}^{-1}$ at 21 LST on 13 August, 2012 at Shionomisaki, which is located $170 \mathrm{~km}$ south of Uji. Moist convections could occur anywhere around Kyoto due to the humid air supply near the surface in proximity to the stationary front, south of which the MCSs were generated. GEONET-derived PWV values at 21 LST on 13 August, 2012 at Shionomisaki and Uji were more than $60 \mathrm{~mm}$ and this fact suggests that CAPE value was also high in Uji. Figure 1 shows movement of a precipitation cell, which was part of a back-building type MCS, south of Kyoto. A new precipitation cell, which passed over the Uji campus within $30 \mathrm{~min}$, was observed south-west of the Uji campus at 2000 LST on 13 August, 2012.

\subsection{GNSS-based observations of PWV}

Temporal variations of GNSS-derived PWV and surface rainfall amounts derived from a rain gauge associated with the passage of the precipitation cell were observed at the Uji campus (Fig. 2). PWV data used here was derived from the GNSS receiver at the Uji campus, which is one of the receivers of the hyper-dense GNSS network used by the authors in earlier studies (Realini et al. 2012; Sato et al. 2013). Precipitation intensity at the GNSS station rapidly increased from 2010 LST on 13 August, 2012, reached a maximum of more than $60 \mathrm{~mm} \mathrm{~h}^{-1}$ within a few minutes, and diminished by 2020 LST. The GNSS-derived PWV started to increase approximately $10 \mathrm{~min}$ before the intensification of surface precipitation. As a result, PWV value increased by approximately $4 \mathrm{~mm}$ in $10 \mathrm{~min}$. 

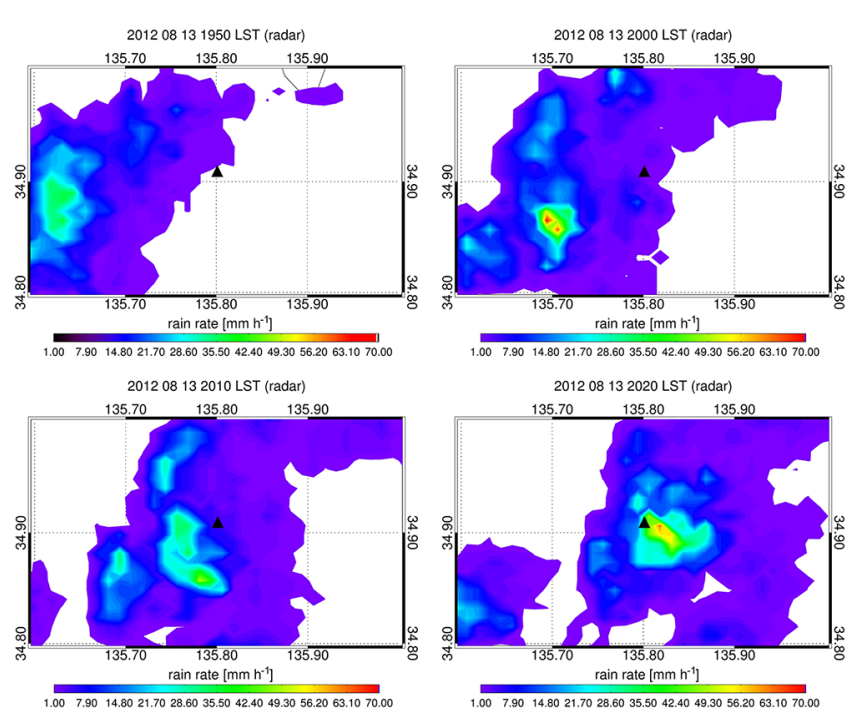

Fig. 1. Maps of precipitation intensity observed by weather radar in 10 min intervals from 1950 LST to 2020 LST on August 13. The location of the Uji campus is indicated by the " $\boldsymbol{\Delta}$ " symbol.

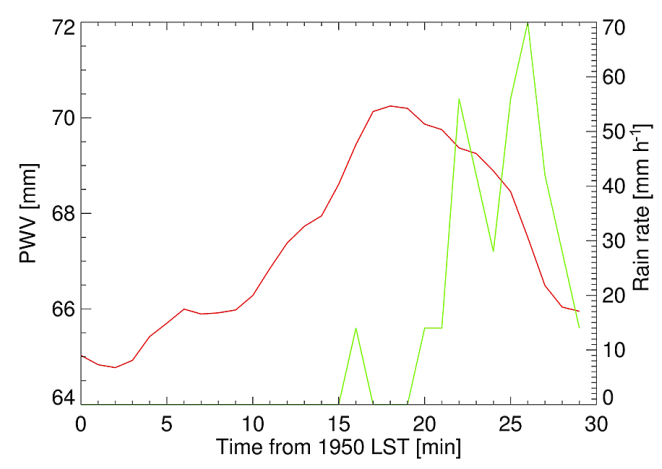

Fig. 2. Temporal variations of GNSS-PWV (red) and precipitation intensity (green) observed at the Uji campus from 1950 LST to 2020 LST on August 13.

\section{Simulation results}

\subsection{Design of the simulation and validation of the model data}

Analyzed numerical model data were derived from the Japan Meteorological Agency Non-hydrostatic Model (JMA-NHM) (Saito et al. 2007). First, numerical simulation using a horizontal grid interval of $2 \mathrm{~km}$ ( $2 \mathrm{~km}-\mathrm{NHM})$ were performed to express unstable background condition and the MCS south of Kyoto. The $2 \mathrm{~km}$-NHM has $451 \times 451$ horizontal grid points and a horizontal domain centered at $35^{\circ} \mathrm{N}, 135^{\circ} \mathrm{E}$ on a Lambert conformal projection. The initial and boundary conditions were set on the basis of JMA mesoscale analysis data (NPD/JMA 2013). It is commonly known that phenomena expressible by numerical models have horizontal scales at least more than 5 times that of the models' grid intervals. Since we focus on water vapor variations within few kilometers, we conducted downscaling to a horizontal grid interval of $250 \mathrm{~m}$ ( $250 \mathrm{~m}-\mathrm{NHM})$. The $250 \mathrm{~m}-\mathrm{NHM}$ has $161 \times 161$ horizontal grid points and a horizontal domain centered at $34.88^{\circ} \mathrm{N}, 135.77^{\circ} \mathrm{E}$ on a Lambert conformal projection. Three-ice bulk microphysics was used in both experiments (Lin et al. 1983; Murakami et al. 1990), with no cumulus parameterization. A hybrid terrain following coordinate is adopted as the vertical coordinate and the vertical resolution was 50 levels from the surface to the model top $(21801 \mathrm{~m})$ in both models. The lowest atmospheric level was $20 \mathrm{~m}$ above the surface, and the depth of the layers
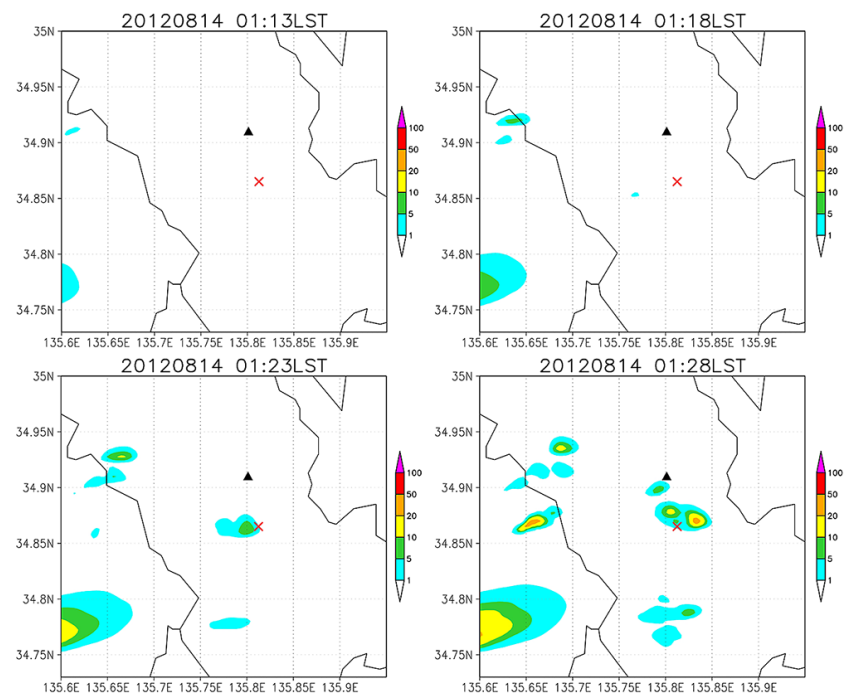

Fig. 3. Time variation of precipitation intensity $(\mathrm{mm} \mathrm{h}-1)$ simulated by the $250 \mathrm{~m}$ grid interval simulation. The location of the Uji campus is indicated by the black " $\boldsymbol{\Delta}$ " symbol. Simulated PWV variation at the point indicated by the red " $\times$ " symbol was compared with observations.

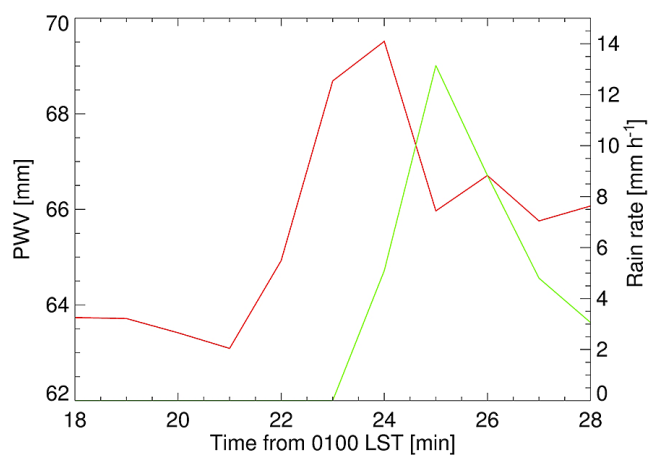

Fig. 4. Time variations of PWV (red) and precipitation intensity (green) as reproduced by the $250 \mathrm{~m}-\mathrm{NHM}$ simulation at the point indicated by the red "x" symbol in Fig. 3.

increased from $40 \mathrm{~m}$ to $886 \mathrm{~m}$ as their height increased. The prognostic variables were wind components, temperature, pressure and all water-related quantities such as vapor, rain, clouds, snow, graupel, and ice clouds (all three-dimensional).

Although experiments had been conducted by setting initial times of $2 \mathrm{~km}-\mathrm{NHM}$ and $250 \mathrm{~m}-\mathrm{NHM}$ as 1800 LST and 1900 LST on 13 August, 2012 respectively, the observed precipitation cell was not reproduced. In contrast, if we set initial times as 0000 LST and 0100 LST on 14 August, 2012 for $2 \mathrm{~km}-\mathrm{NHM}$ and $250 \mathrm{~m}$-NHM, respectively, a back-building type MCS was simulated by $2 \mathrm{~km}-\mathrm{NHM}$ and a precipitation cell which was part of the MCS and initiated around Uji was simulated by $250 \mathrm{~m}-\mathrm{NHM}$. Figure 3 shows the precipitation intensity maps simulated by the $250 \mathrm{~m}-\mathrm{NHM}$. Surface precipitation around Uji started at 0118 LST. Subsequently, the cell continued to grow and reached an intensity of more than $10 \mathrm{~mm} \mathrm{~h}^{-1}$ at $0128 \mathrm{LST}$.

Although the initiation place of the simulated cell was shifted of about $5 \mathrm{~km}$ southward with respect to the observation, the difference of the initiation place is small and its moving direction agreed well with the observation result. In addition, the fact that the observed and simulated precipitation cells were both part of the same type of MCSs indicates that these cells were generated under ambient conditions very similar to those of the observation result. Figure 4 shows the temporal variations of PWV and the precipitation intensity as reproduced by the $250 \mathrm{~m}-\mathrm{NHM}$ simulation. These values were calculated at a location approximately 
$5.5 \mathrm{~km}$ south-southeastward of the Uji campus, indicated in Fig. 3. A rapid PWV increase prior to the intensification of surface precipitation was successfully simulated and this result suggests the validity of the numerical modeling, particularly regarding the relationship between water vapor variation and rainfall intensity. For the above reasons, the data of $250 \mathrm{~m}-\mathrm{NHM}$ is worth using for analysis at least to investigate the physics of the observed precipitation cell.

\subsection{Simulated meso-y scale PWV fluctuations}

Figure 5 shows maps of PWV and precipitation intensity associated with the precipitation cell and its evolution over time in $6 \mathrm{~min}$ intervals from the $250 \mathrm{~m}$-NHM. The indicated horizontal domain has an area of $12.8 \mathrm{~km} \times 8.9 \mathrm{~km}$. The PWV values in the eastern side have relatively lower values, because mountains cover this region. Surface precipitation started at 0118 LST. We focused on the local PWV maximum indicated by a " $\boldsymbol{\Delta}$ " in the figure at $0118 \mathrm{LST}$. This maximum formed before the start of surface precipitation and can be recognized by its shape at 0106 LST, $12 \mathrm{~min}$ before the start of rainfall. The horizontal velocity of the local PWV maximum was estimated by assuming constant movement from 0106 LST to 0130 LST and the locations of the local PWV maxima for each time are indicated by " $\boldsymbol{\Delta}$ " symbols in Fig. 5. Vertical profiles of water vapor and wind at these points were analyzed to investigate the mechanism for the PWV increase associated with the cumulonimbus cloud.

Figure 6a shows temporal variations of the PWV anomaly and VIL (vertically integrated liquid water) at the local PWV maximum. The PWV started to increase at $0102 \mathrm{LST}, 16 \mathrm{~min}$ before
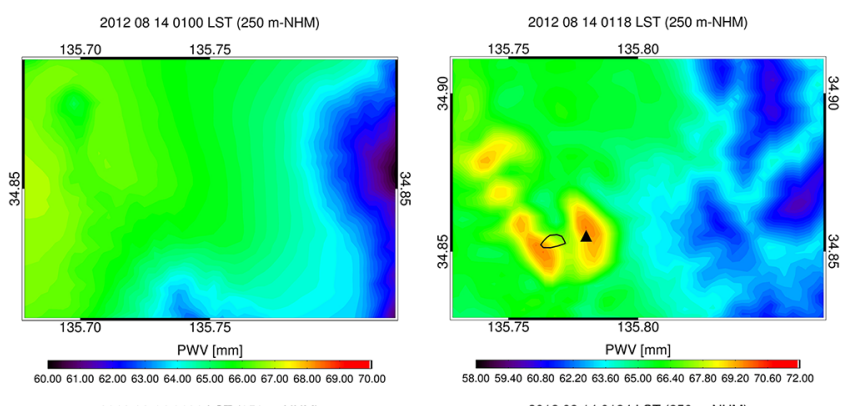

201208140106 LST (250 m-NHM)
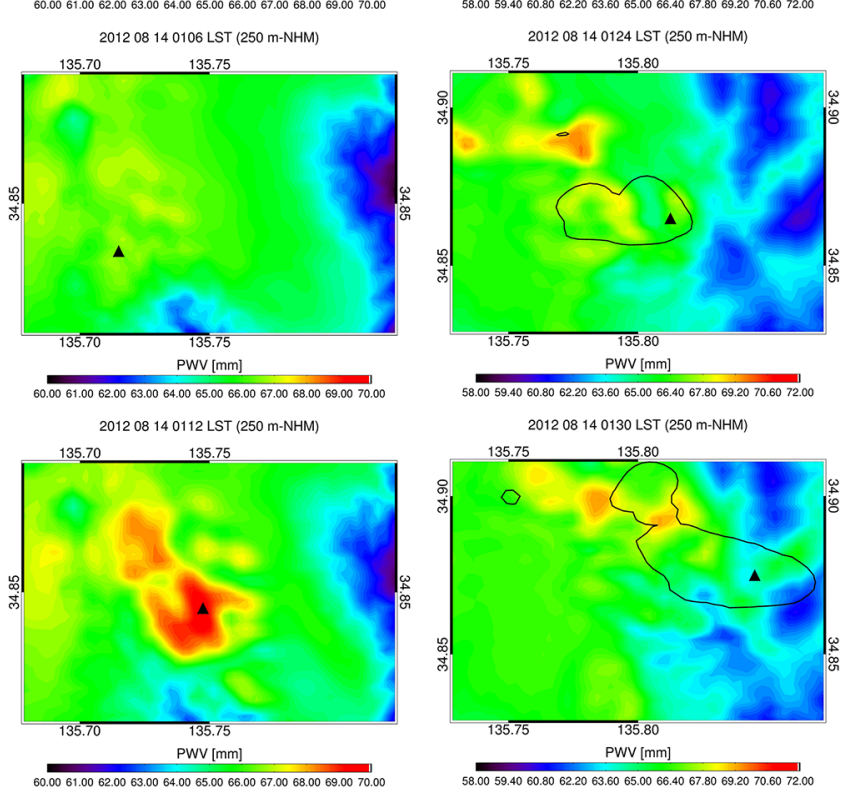

Fig. 5. Maps of PWV (shade) and precipitation intensity (contour: $1 \mathrm{~mm}$ $\mathrm{h}^{-\mathrm{p}}$ ) at time steps of $6 \mathrm{~min}$ reproduced by the $250 \mathrm{~m}$ grid interval simulation from 0100 LST to 0130 LST on August 14. Vertical profiles of physical values were analyzed by tracing the convection cell at the points depicted by " $\boldsymbol{\Delta}$ " symbol. The " $\boldsymbol{\Delta}$ " symbol at 0124 LST corresponds to the red " $\times$ " symbol in Fig. 3. the start of the surface rainfall. Figure $6 \mathrm{~b}$ shows the vertical distribution of the vertical wind velocities and its temporal evolution. Before 0118 LST, a downward wind region can be seen at an elevation of approximately $2 \mathrm{~km}$, with upward wind motion occurring below this region. After 0118 LST, upward wind velocities became strong and deep convection was generated. The downward wind region prior to 0118 LST was likely an inversion layer. Before 0118 LST, upward wind velocities were more than $4 \mathrm{~m} \mathrm{~s}^{-1}$ and we can deduce that a shallow free convection had already generated under the downward wind region. Figure $6 \mathrm{~b}$ shows a strong upward wind region at a height of $1 \mathrm{~km}$ that can be traced back to 0107 LST. In addition, the rate of the PWV increase became large at 0107 LST. Therefore, the initiation of the free convection occurred at approximately 0107 LST. Before 0107 LST, horizontal surface wind convergence can be seen in Fig. $6 \mathrm{c}$ and this convergence caused the lifting of an air parcel around $1 \mathrm{~km}$ elevation. The maximum horizontal convergence formed at an elevation of $1.7 \mathrm{~km}$ at $0118 \mathrm{LST}$, following the breakthrough of the inversion layer (Fig. 6c). The humid boundary layer thickened with time due to shallow convection and the following horizontal convergence of moisture near the surface from 0107 LST to 0118 LST (Fig. $6 \mathrm{~d})$, resulting in the increase of PWV.

Figure 7 (left) shows the vertical distributions of equivalent potential temperature and the saturated equivalent potential temperature at $0105 \mathrm{LST}$. An inversion layer can be seen between 2.2 and $3.5 \mathrm{~km}$ elevation and a strong convective instability is evident between 1.00 and $1.28 \mathrm{~km}$ elevation. Air at elevations between 0.73 and $1.08 \mathrm{~km}$ was saturated with water vapor at $0105 \mathrm{LST}$ and it was confirmed that an air parcel in this layer was located at the LFC (level of free convection) (Fig. 7 (left)). The height of the convectively unstable layer increased with time after the shallow convection was initiated at 0107 LST and the inversion layer can no longer be seen at 0120 LST after its breakthrough at 0118 LST.

\section{Summary and discussion}

Variations of water vapor associated with a meso- $\gamma$ scale convection were investigated using a non-hydrostatic mesoscale
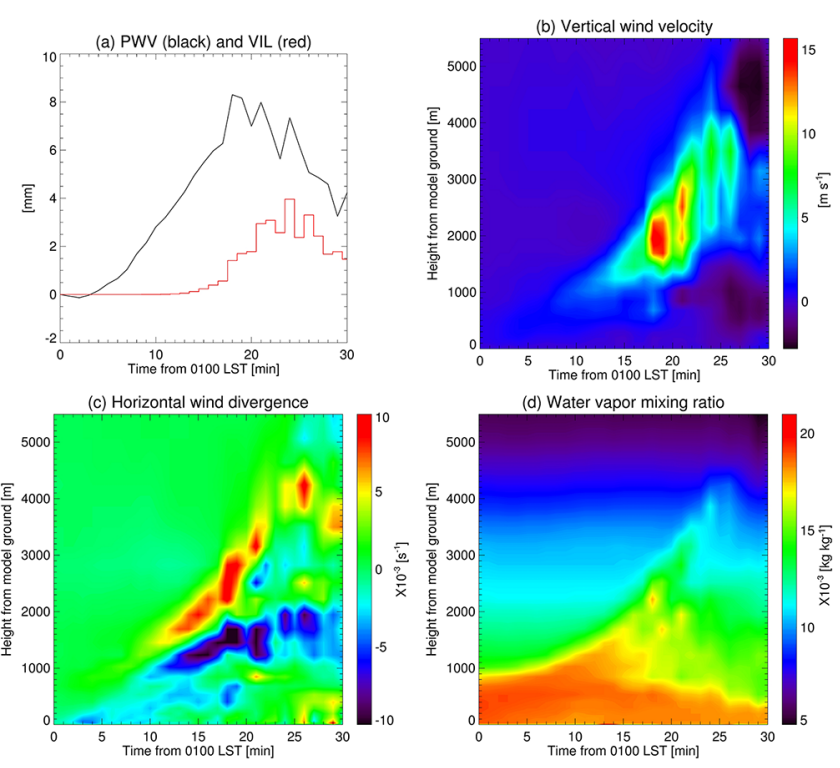

Fig. 6. (a) Time variations of PWV increase from the initial time of the $250 \mathrm{~m}$ grid interval simulation (line) and the Vertically Integrated Liquid water (VIL) (boxes) within the convection. (b) Vertical distributions of vertical wind velocity and its time evolution within the convection. (c) Vertical distributions of horizontal wind divergence and its time evolution within the convection. (d) Vertical distributions of water vapor mixing ratio and its time evolution within the convection. Location of profiles of each times are indicated by the " $\boldsymbol{\Delta}$ " symbol in Fig. 5. 

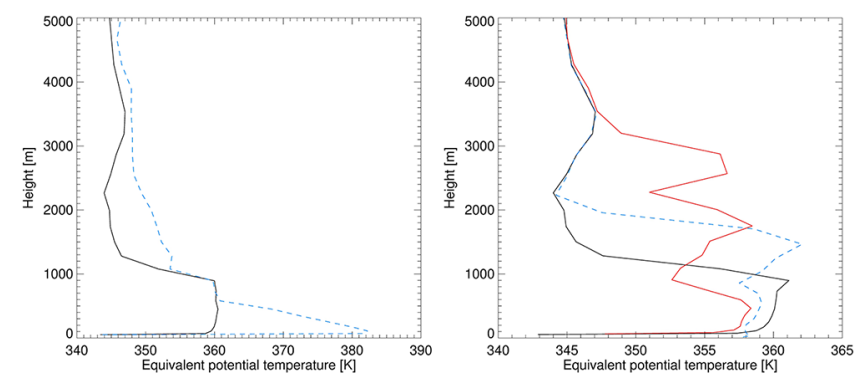

Fig. 7. (Left) Vertical distributions of equivalent potential temperature (black) and saturated equivalent potential temperature (blue broken line) at 0105 LST. (Right) Vertical profiles of equivalent potential temperature within the convection cell at 0107 LST (black), 0114 LST (blue broken line) and 0120 LST (red). Locations of each profile are indicated by the " $\mathbf{\Delta}$ "symbol in Fig. 5.

model and observational data. Temporal variations of PWV and surface precipitation intensity associated with the passage of a convection cell that was part of a back-building type MCS, which brought heavy rainfall to Uji on 13-14 August, 2012, were observed using a GNSS receiver and rain gauge. Based on observations at the Uji campus, PWV values started to increase rapidly approximately $10 \mathrm{~min}$ before the intensification of surface precipitation.

A downscaling simulation was performed to simulate water vapor variations within a cumulonimbus cloud that passed over the Uji campus using the JMA-NHM by setting a horizontal grid interval to $250 \mathrm{~m}$. Although there is a small gap in the formation time between the simulated and observed rain bands, back-building type MCSs were simulated by a 2 km-NHM. Furthermore, the validity of the downscaling results was confirmed because the $250 \mathrm{~m}$ grid interval simulation successfully simulated the observed rapid PWV increase prior to the surface rainfall.

In the model, PWV associated with moist convection began to increase at $0102 \mathrm{LST}, 16 \mathrm{~min}$ before the start of surface rainfall (at 0118 LST) and local maximums of PWV were formed prior to the rainfall. Analysis of output data revealed that free convection was initiated at $0107 \mathrm{LST}, 11 \mathrm{~min}$ before the surface rainfall, due to the lifting of an air parcel at approximately $1 \mathrm{~km}$ elevation. The air parcel became buoyant because the air column around $1 \mathrm{~km}$ elevation was highly convectively unstable, allowing the air parcel to reach the LFC, and the horizontal wind had previously converged near the surface before the initiation of the free convection. It was also revealed that it took $11 \mathrm{~min}$ for the free convection to rise above a stable inversion layer that existed between 2.2 and $3.5 \mathrm{~km}$ elevation to generate deep convection. Therefore, the PWV increase from 0102 to 0107 LST was caused by surface wind convergence and the PWV increase from 0107 to 0118 LST was caused by shallow free convection under the inversion layer. Then, rainfall at the surface started at 0118 LST.

During this heavy rainfall event, a large area was affected by high PWV values of more than $60 \mathrm{~mm}$. Under such atmospheric conditions, the distribution of surface wind convergence may be more important than local convergence of moisture to determine where the convection is initiated. However, even under such conditions, observation of the local distribution of PWV is useful for monitoring convective activity because local convergence of moisture is detectable from PWV maps and air parcels require time to form deep convections with the presence of an inversion layer.

\section{Acknowledgements}

The numerical model used in this study was provided by the JMA and the initial and boundary data were provided by the "Meteorological Research Consortium." This work is partly supported by a Grant-in-Aid for the Japan Society for the Promotion of Science (JSPS) Fellows. The authors appreciate the cooperation offered by Dr. Kazutoshi Sato in setting up GNSS and rain gauge observation instruments. The authors would like to express their gratitude to Dr. Takuya Kawabata, Dr. Hiromu Seko, and Dr. Yoshinori Shoji of Meteorological Research Institute for providing useful comments and suggestions. We extend our thanks to Dr. Atsuki Shinbori for his support to use IDL software and the other members of the Tsuda Laboratory of RISH, Kyoto University, for providing useful comments.

\section{References}

Bodine, D., P. L. Heinselman, B. L. Cheong, R. D. Palmer, and D. Michaud, 2010: A case study on the impact of moisture variability on convective initiation using radar refractivity retrievals. J. Appl. Meteorol. Clim., 49, 1766-1788.

Inoue, H. Y., and T. Inoue, 2007: Characteristics of the water-vapor field over the Kanto district associated with summer thunderstorm activities. SOLA, 3, 101-104.

Ishihara, M., and K. Takara, 2013: Organization of mesoscale convective systems causing heavy rainfall and flash flood around Uji, Kyoto on 14 August 2012. Disaster Prev. Res. Inst. Annuals, 56B, 79-86.

Japan Meteological Agency, 2013: Outline of the operational numerical weather prediction at the Japan Meteorological Agency. WMO Technical Progress Report on the Global Data Processing and Forecasting System (GDPFS) and Numerical Weather Prediction (NWP) Research, 28-36.

Lin, Y.-L., R. D. Farley, and H. D. Orville, 1983: Bulk parametarization of the snow fields in a cloud model. J. Climate Appl. Meteor., 22, 1065-1092.

Murakami, M., 1990: Numerical modeling of dynamical and microphysical evolution of an isolated convective cloud. the 19 July 1981 CCOPE cloud. J. Meteor. Soc. Japan, 68, $107-128$.

Realini, E., T. Tsuda, K. Sato, M. Oigawa, and Y. Iwaki, 2012: Analysis of the temporal and spatial variability of the wet troposphere at a local scale by high-rate PPP using a dense GNSS network. ION GNSS 2012, At Nashville, Tennessee, USA (proceedings).

Saito, K., J. Ishida, K. Aranami, T. Hara, T. Segawa, M. Narita, and Y. Honda, 2007: Nonhydrostatic atmospheric models and operational development at JMA. J. Meteor. Soc. Japan, 85B, 271-304.

Sato, K., E. Realini, T. Tsuda, M. Oigawa, Y. Iwaki, Y. Shoji, and H. Seko, 2013: A high-resolution, precipitable water vapor monitoring system using a dense network of GNSS receivers. J. Disaster Research, 8, 37-47.

Seko, H., N. Nakamura, Y. Shoji, and T. Iwabuchi, 2004: The meso- $\gamma$ scale water vapor distribution associated with a thunderstorm calculated from a dense network of GPS receivers. J. Meter. Soc. Japan, 82, 569-586.

Seko, H., Y. Shoji, and F. Fujibe, 2007: Evolution and air flow structure of a Kanto thunderstorm on 21 July, 1999 (the Nerima Heavy Rainfall Event). J. Meter. Soc. Japan, 85, 455-477.

Shoji, Y., H. Nakamura, T. Iwabuchi, K. Aonashi, H. Seko, K. Mishima, A. Itagaki, R. Ichikawa, and R. Ohtani, 2004: Tsukuba GPS dense net campaign observation: Improvement in GPS analysis ofslant path delay by stacking one-way postfit phase residuals. J. Meteor. Soc. Japan, 82, 301-314.

Manuscript received 8 December 2014, accepted 17 February 2015 SOLA: https://www.jstage.jst.go.jp/browse/solal 